\section{Repeated spontaneous clearance of hepatitis C virus infection in the setting of long-term non-progression of HIV infection}

\author{
Genevieve Kerkerian, ${ }^{1,2}$ \\ Arshia Alimohammadi, ${ }^{1}$ \\ Tyler Raycraft, ${ }^{1}$ Brian Conway ${ }^{1}$
}

${ }^{1}$ Vancouver Infectious Diseases Center; ${ }^{2}$ Department of Medicine, University of British Columbia, Vancouver, Canada

\begin{abstract}
Hepatitis C Virus (HCV) and human immunodeficiency virus (HIV) are global pandemics that affect 170 million and 35 million individuals, respectively. Up to $45 \%$ of individuals infected with $\mathrm{HCV}$ clear their infections spontaneously - correlating to factors like aboriginal descent and some host specific immune factors. HIV, however, establishes true latency in infected cells and cannot be cured. In the setting of longterm non-progressors (LTNPs) of HIV, a state of immune preservation and low circulating viral load is established. Regarding $\mathrm{HIV} / \mathrm{HCV}$ co-infection, little is known about the relationship between spontaneous clearance of HCV infection and long-term control of HIV infection without medical intervention. We describe a case of a HIVinfected female defined as a LTNP in whom spontaneous clearance of HCV was documented on multiple occasions. Similar cases should be documented and identified in an effort to develop novel hypotheses about the natural control of these infections and inform research on immune-based interventions to control them.
\end{abstract}

\section{Introduction}

Hepatitis C Virus (HCV) epidemic accounts for $>185$ million infections worldwide. ${ }^{1}$ An acute infection is usually asymptomatic, and is only very rarely associated with life-threatening disease. Approximately $15-45 \%$ of infected individuals clear their infection spontaneously, without any medical intervention. ${ }^{2}$ Female sex, being aboriginal descendant, symptomatic acute hepatitis and some host specific immune factors are associated with more frequent spontaneous HCV clearance. ${ }^{3}$

Human immunodeficiency virus (HIV) infection is another global pandemic affecting more than 35 million individuals. ${ }^{4}$ In the majority of cases, it is has the characteris- tics of a chronic, progressive infection. As HIV establishes true latency in infected cells, this infection cannot be cured. However, in a small minority of infected individuals, a status of long-term non-progression (LTNP) can be established, with a preserved immune system and low circulating HIV viral load. Patients in whom this status is achieved are termed long-term non-progressors (LTNPs). ${ }^{5}$ Clinically, LTPNs maintain high CD4 counts, and do not develop symptoms of AIDS, exhibiting a detectable, although low, HIV viral load $(<1000$ copies $/ \mathrm{mL})$, while elite controllers maintain an undetectable viral load without antiretroviral therapy. ${ }^{5}$

In Canada, approximately $17 \%$ of HIVinfected individuals are co-infected with $\mathrm{HCV}$, the majority of whom are current or recent injection drug users. ${ }^{6,7}$ There is limited knowledge about the relationship between spontaneous clearance of $\mathrm{HCV}$ infection and long-term control of HIV infection without the benefit of antiretroviral therapy. We describe a case of an HIVinfected female who was an established LTNP in whom spontaneous clearance of $\mathrm{HCV}$ was documented on multiple occasions.

\section{Case Report}

We report a 52-year-old woman of mixed Caucasian and aboriginal heritage with a 30-year history of injection drug use. Since 1997, she has been injecting heroin and smoking cocaine intermittently until 2004, when she attempted to abstain and was successful until 2005. Unfortunately, she relapsed onto heroin addiction in 2005, and continued to inject until her latest visit on December $5^{\text {th }}, 2016$. In 1997, she was tested for HIV and HCV and was reported to be negative for both. She lives in the Vancouver Downtown East Side where the most prevalent HCV genotype is 1a. Based on chart review, the patient presented regularly for follow-up regarding HIV infection, and recent injection drug use prompted $\mathrm{HCV}$ testing. Antibodies to HCV were first detected in 1999, with a corresponding test for viremia being negative at that time, consistent with acquisition and spontaneous clearance of HCV infection between 1997 and 1999. HIV antibody testing was first reported as positive in 2003, with HIV viral load that was undetectable without the benefit of antiretroviral therapy. For HIV viral load measurements, Roche COBAS Ampliprep/COBAS Taqman quantitative HIV-1 RNA assay was used (F. HoffmannLa Roche AG, Basel, Switzerland). HIV viral load tests performed between 2003 and 2009 were also below the limit of detec-
Correspondence: Arshia Alimohammadi, Vancouver Infectious Diseases Center, 1200 Burrard st, Vancouver, BC, V6Z 2C7, Canada. Tel.: +1.604.642.6429 ext 308 .

E-mail: arshia.alimohammadi@vidc.ca

Key words: Hepatitis C, HIV, HCV spontaneous clearance, HIV long-term non-progressor.

Contributions: the authors contributed equally.

Conflict of interest: the authors declare no potential conflict of interest.

Received for publication: 23 March 2017

Revision received: 7 July 2017.

Accepted for publication: 8 July 2017.

This work is licensed under a Creative Commons Attribution-NonCommercial 4.0 International License (CC BY-NC 4.0).

(C) Copyright G. Kerkerianet al., 2017 Licensee PAGEPress, Italy

Infectious Disease Reports 2017; 9:7142 doi:10.4081/idr.2017.7142

tion $(<40$ copies $/ \mathrm{mL})$. During this time, the patient is classified as an elite controller, as her viral load is consistently undetectable. For all HCV viral load measurements, Roche's COBAS Amplicor/Taqman quantitative HCV RNA test was used, with a detection range of 12-100,000,000 IU/mL and Qualitative HCV tests with Amplicor PCR was used to confirm the presence/ absence of circulating HCV RNA.

She was found to be viremic for $\mathrm{HCV}$ genotype 1a/1b in April 2009. In June 2009, HCV RNA was once again undetectable without the benefit of antiviral intervention. During this time, HBV antibody testing for $\mathrm{HBs}$ and $\mathrm{HBc}$ was also preformed, and found to be positive.

Elevated transaminase were detected in July 2014 (AST:50 U/L, ALT: 76 U/L), suggesting a new episode of HCV infection but HCV RNA testing remaining negative when last tested in March 2016. Once again, no treatment directed against HCV infection had ever been administered to this patient. Relevant laboratory results are summarized in Table 1. With respect to her HIV infection, she never received antiretroviral therapy. Plasma viral load results have been consistently below 200 copies/mL, with a single value of 1527 copies/mL in April 2009. CD4 cell counts, with a single exception in April 2009 (associated with detectable HCV RNA) have been within the normal range. HIV-related laboratory parameters are also summarized in Table 1. 


\section{Discussion}

$\mathrm{HCV}$ and HIV infections are recognized world-wide pandemics, with co-infection particularly affecting injection drug users. HCV affects more than 240,000 Canadians, including approximately 15,000 co-infected with HIV, such as our patient. ${ }^{7} \mathrm{HCV} / \mathrm{HIV}$ co-infection is generally associated with a lower likelihood of spontaneous HCV clearance, more rapid HCV-related disease progression and higher rates of clinical complications. ${ }^{8}$ In our HIV LTNP patient, we have documented repeated instances of spontaneous clearance of $\mathrm{HCV}$ viremia, one of which preceded the acquisition of HIV infection. A review of the literature reveals a number of instances of HIV/HCV coinfected individuals on antiretroviral therapy with spontaneous clearance of $\mathrm{HCV}$ infection..$^{8-11}$ There are a few reports of single episodes of spontaneous clearance of $\mathrm{HCV}$ infection in the setting of HIV-related LTNP, including some patients defined as elite controllers, defined as individuals with HIV plasma viral load measures that are consistently undetectable without the benefit of antiretroviral therapy. ${ }^{12,13}$ To our knowledge, this case report represents the first documentation of repeated instances of clearance of HCV infection in the setting of HIV-related LTNP.

Although pre-existing HIV infection has been identified as a negative predictor of spontaneous clearance of HCV infection, it does not preclude its occurrence. A number of factors may help predict spontaneous clearance, such as treatment-associated immune reconstitution and the presence of certain genetic polymorphisms (IL28B-CC and HLA-B57 among them)., ${ }^{9,14-16}$ In a Spanish study of $\mathrm{HIV} / \mathrm{HCV}$ co-infected individuals, $75 \mathrm{HIV}$ controllers, (including 33 LTNP and 42 elite controllers) were compared to 261 other subjects with a broad range of HIV plasma viral load measures above 1000 copies/mL. All HIV controllers, including elite controllers, had lower circulating $\mathrm{HCV}$ viral load measures, and the presence of the HLA-B57 allele was predictive of lower values across all groups. ${ }^{12}$ In another cross-sectional study, co-infection with HIV (in the condition of either LTNP or elite controller) was associated with an increased likelihood of spontaneous HCV clearance where $23.3 \%$ of such individuals, as compared to $9.1 \%$ of $350 \mathrm{HCV}$ monoinfected and only $6.5 \%$ of 350 non-LTNP HIV co-infected individuals, spontaneously cleared their $\mathrm{HCV}$ infection. ${ }^{13}$ While the $9.1 \%$ rate of spontaneous clearance quoted in this study is lower than the WHO's estimated $20 \%$ value, ${ }^{2,13}$ this is likely due to a relatively small sample size. However, the significant conclusion that HCV monoinfected individuals demonstrate a lower rate of spontaneous clearance when com- pared to HIV co-infected LTNPs remains.

It is also interesting to speculate as to any contribution the patient's environment or exposure history may have had in the outcome of her HIV and HCV infections. Researchers in Montreal have identified some degree of natural immunity to HIV infection in highly exposed uninfected African female sex workers due to polymorphisms in the IRF-1 gene. ${ }^{5}$ Furthermore, one study showed that $\mathrm{HCV}$ reinfection occurred in $50 \%$ of injection drug users who previously spontaneously controlled their primary HCV infection. Although viral clearance occurs in approximately $25 \%$ of patients with primary infections, spontaneous viral clearance was observed in $83 \%$ of re-infected patients. ${ }^{17}$ In our patient, we may speculate that specific host factors present in the context of repeated low-level exposure to HIV and HCV, could have produced a state of natural immunity that, if identified, could help us learn more about natural immunity to these chronic viral infections. Her continual re-infection with $\mathrm{HCV}$ could have also had a role in providing baseline protection against future persistent $\mathrm{HCV}$ infections.

In one large study of HIV, ${ }^{12}$ loss of control of HIV infection was observed during subsequent acute HCV infection. This was not clearly observed in our patient, except for a single instance of decreasing CD4 cell count and increasing HIV viremia at the

Table 1. Hepatitis C virus and HIV-related laboratory data (1997-2016).

\begin{tabular}{|c|c|c|c|c|c|c|}
\hline Date of testing & $\begin{array}{l}\text { HCV } \\
\text { antibody }\end{array}$ & $\begin{array}{l}\text { Qualitative } \\
\text { HCV RNA }\end{array}$ & $\begin{array}{c}\text { Quantitative } \\
\text { HCV RNA (copies/mL) }\end{array}$ & HCV genotype & $\begin{array}{l}\text { HIV viral load } \\
\text { (copies/mL) }\end{array}$ & $\begin{array}{l}\text { CD4 count } \\
\left(\text { cells/mm } \mathrm{mm}^{3}\right)\end{array}$ \\
\hline 1997 & Negative & Negative & NA & la/lb & NA & NA \\
\hline February 1999 & Positive & Positive & ND & ND & $\mathrm{NA}$ & NA \\
\hline November 2006 & Positive & Negative & NA & la/lb & 62 & ND \\
\hline September 2007 & Positive & Negative & NA & NA & 68 & ND \\
\hline July 2008 & Positive & Negative & NA & $\mathrm{NA}$ & 79 & 770 \\
\hline April 2009 & Positive & Positive & ND & la/lb & 1527 & 260 \\
\hline June 2009 & Positive & Negative & NA & $\mathrm{NA}$ & NA & $\mathrm{NA}$ \\
\hline September 2009 & Positive & Positive & ND & la/lb & 44 & 640 \\
\hline November 2009 & Positive & Positive & ND & la/lb & 75 & 730 \\
\hline July 2010 & Positive & Positive & ND & la/lb & 129 & 480 \\
\hline October 2011 & Positive & Negative & $\mathrm{NA}$ & $\mathrm{NA}$ & 56 & 560 \\
\hline September 2012 & Positive & Negative & NA & NA & $<40$ & 590 \\
\hline September 2013 & Positive & Negative & NA & NA & $<40$ & 650 \\
\hline April 2013 & Positive & Positive & ND & la/lb & 40 & 650 \\
\hline June 2014 & Positive & Positive & $<15$ & la/lb & $<40$ & 450 \\
\hline July 2014 & Positive & Positive & $<15$ & la/lb & ND & ND \\
\hline July 2014 & Positive & Negative & $\mathrm{NA}$ & $\mathrm{NA}$ & ND & ND \\
\hline October 2014 & Positive & Negative & $\mathrm{NA}$ & $\mathrm{NA}$ & $<40$ & 500 \\
\hline January 2015 & Positive & Negative & NA & $\mathrm{NA}$ & 240 & 530 \\
\hline December 2016 & Positive & Negative & NA & NA & $<40$ & 650 \\
\hline
\end{tabular}

$\mathrm{NA}$, not available; $\mathrm{ND}$, not done 
time of HCV viremia in April 2009. Her HIV-related LTNP status was quickly restored when this repeated occurrence of hepatitis C viremia was cleared spontaneously. It is further interesting to note that she developed natural (not vaccineinduced) protective immunity to HBV following acquisition of this infection in nature in 2009, as HIV infected individuals are far less likely to develop natural immunity to HBV compared to non-HIV infected individuals $(17 \%$ compared to $>90 \%){ }^{18}$

The patient's HCV genotype was consistently $1 \mathrm{a} / 1 \mathrm{~b}$ when testing was performed. There are two possible explanations for this persistence - the patient was either repeatedly infected from the same source (such as consistently needle-sharing with a chronically infected individual) or the patient maintained the same infection, despite lab results demonstrating an undetectable plasma viral load. Therefore, one further important point of speculation in this case is the possibility that the patient's repeated suppressions of HCV viral load did not, in fact, represent instances of spontaneous clearance, but rather chronic persistence of the same HCV infection with cyclic viral suppression. For example, numerous studies have identified low-level intra-hepatic viral replication in chronic $\mathrm{HCV}$ infection. ${ }^{18-20}$ While a viral reservoir within the liver associated with clearance from the circulation is uncommon, it is a possibility that must be considered in this setting. Differentiating between these possibilities will remain a limitation of this case, as samples are not available to determine if different $\mathrm{HCV}$ genotypes or isolates are involved, or if we are observing near-complete clearance of the same virus on multiple occasions, and low-level recrudescence of a single preexisting infection on multiple occasions.

It is important to point out limitations of this report. Laboratory data remain incomplete. The pattern of acquisition and repeated clearance of HCV cannot be precisely defined as specifically timed longitudinal blood samples have not been collected. Samples were not available to determine if different $\mathrm{HCV}$ genotypes or isolates were involved, or if we were observing nearcomplete clearance of the same virus on multiple occasions, and low-level recrudescence of a single pre-existing infection on multiple occasions

\section{Conclusions}

We describe an HIV-infected woman, an established LTNP (progressing to elite controller status), with repeated documented episodes of spontaneous clearance of hepatitis C-related viremia. Databases of HIV LTNPs should be examined to identify similar cases who may be exposed repeatedly to HCV and fail to establish persistent infection. This may help develop novel hypotheses about natural control of both $\mathrm{HIV}$ and $\mathrm{HCV}$, and provide new insight on various host-mediated factors that result in a continually controlled HIV infection and continuous spontaneous clearance of $\mathrm{HCV}$ infection.

\section{References}

1. Messina J, Humphreys I, Flaxman A, et al. Global distribution and prevalence of hepatitis $\mathrm{C}$ virus genotypes. Hepatology 2015;61:77-87.

2. World Health Organization. Hepatitis C. 2015. Available from: http://www.who.int/mediacentre/factsheets/fs164/en/. Accessed on: January 2015.

3. Grebely J, Prins M, Hellard M, et al.Hepatitis $\mathrm{C}$ virus clearance, reinfection, and persistence, with insights from studies of injecting drug users: towards a vaccine. Lancet Infect Dis 2012;12:408-14.

4. World Health Organization. HIV 10 facts. 2014 Available from: http:/www.who.int/features/factfiles/hi v/en/. Accessed on: 4 July 2015.

5. Poudrier J, Thibodeau V, Roger M. Natural immunity to HIV: a delicate balance between strength and control. Clin Dev Immunol 2012;2012:875821.

6. Centers for Disease Control and Prevention. HIV and Viral Hepatitis. 2014. Available from: http://www.cdc.gov/hiv/pdf/library_fac tsheets_HIV_and_viral_Hepatitis.pdf.

7. Public Health Agency of Canada. Hepatitis C in Canada: 2005-2010 Surveillance Report. Centre for Communicable Diseases and Infection Control, Infectious Disease Prevention and Control Branch, Public Health Agency of Canada. 2011.

8. Vispo E, Barreiro P, Plaza Z et al. Spontaneous hepatitis $\mathrm{C}$ virus clearance in HIV patients with chronic hepatitis $\mathrm{C}$ bearing IL28B-CC alleles using antiretroviral therapy. Aids 2014;28:1473.

9. Kaung A, Sundaram V, Tran TT. Spontaneous clearance of hepatitis $\mathrm{C}$ virus in a patient co-infected with hepa- titis $\mathrm{C}$ virus and human immunodeficiency virus: a case report. J Gastrointestin Liver Dis 2014;23:325-7.

10. Fialaire P, Payan C, Vitour D. Sustained disappearance of hepatitis $\mathrm{C}$ viremia in patients receiving protease inhibitor treatment for human immunodeficiency virus infection. J Infect Dis 1999;180: 574-5.

11. Gonzalez VD, Falconer K, Blom KG, et al. High levels of chronic immune activation in the T-cell compartments of patients coinfected with hepatitis $\mathrm{C}$ virus and human immunodeficiency virus type 1 and on highly active antiretroviral therapy are reverted by alpha interferon and ribavirin treatment. J Virol 2009;83:11407-11.

12. Ruiz-Mateos E, Machmach K. Hepatitis $\mathrm{C}$ virus replication in Caucasian HIV controllers. J Viral Hepatitis 2011;18:e350-7.

13. Sajadi MM, Shakeri N, Talwani R. Hepatitis C infection in HIV-1 natural viral suppressors. AIDS 2010;24:1689.

14. Sajadi MM, Redfield RR, Talwani R. Altered T cell subsets in HIV-1 natural viral suppressors (elite controllers) with hepatitis $\mathrm{C}$ infection. AIDS 2013;27:1989-92.

15. Westbrook RH, Dusheiko G. Natural history of hepatitis C. J Hepatol 2014;61:S58-68.

16. Miura T, Brockman MA, Brumme CJ. Genetic characterization of human immunodeficiency virus type 1 in elite controllers: lack of gross genetic defects or common amino acid changes. J Virol 2008;82:8422-30

17. Osburn WO, Fisher BE, Dowd KA, et al. Spontaneous control of primary hepatitis $\mathrm{C}$ virus infection and immunity against persistent reinfection. Gastroenterology 2010;138:315-24.

18. Shire NJ, Welge JA, Sherman KE. Efficacy of inactivated hepatitis A vaccine in HIV-infected patients: a hierarchical bayesian meta-analysis. Vaccine 2006;24:272-9.

19. Chang M, Williams O, Mittler J, et al. Dynamics of hepatitis $\mathrm{C}$ virus replication in human liver. Am J Pathol 2003;163:433-4.

20. Pal S, Shuhart MC, Thomassen L, et al. Intrahepatic hepatitis $\mathrm{C}$ virus replication correlates with chronic hepatitis c disease severity in vivo. J Virol 2006;80: 2280-90. 